\title{
IDENTIFIKASI DAN MITIGASI RISIKO DI OFFSHORE OPERATION FACILITIES DENGAN MENGGUNAKAN METODE FAILURE MODE AND EFFECT ANALYSIS
}

\author{
Ketut Sugiantara*, Minto Basuki \\ Magister Teknik Industri, Fakultas Teknologi Industri, Institut Teknologi Adhi Tama Surabaya \\ Email:ksugiantara65@gmail.com; mintobasuki@yahoo.co.id \\ Artikel masuk : 06-11-2019 \\ Artikel direvisi : 02-12-2019
${ }^{*}$ Penulis Korespondensi \\ Artikel diterima : 21-12-2019
}

\begin{abstract}
Abstrak - Industrialisasi dibidang migas mempunyai risiko kecelakaan kerja tinggi, Operasi kegiatan migas dibagi menjadi dua yaitu offshore dan onshore. Offshore facilities adalah eksplorasi Gas Bumi yang dimiliki oleh PT. $X$ yang berada dilepas pantai utara pulau jawa dengan bentuk konstruksi yang berbeda serta ruang gerak bagi pekerja yang sangat terbatas. Faktor keselamatan dan kesehatan kerja merupakan prioritas utama dalam melaksanakan kegiatan dilakukan di Offshore Facilities. Metode failure mode effect and analysis (FMEA) merupakan metode yang diimplementasikan untuk mengidentifikasi potensi risiko kegagalan proses pekerjaan dengan menentukan dampak dan mengidentifikasi tindakan untuk mengurangi risiko kerja. Tujuan penelitian ini untuk mengetahui faktor yang menjadi penyebab dan mitigasi risiko dengan menyusun rekomendasi perbaikan untuk meminimalisir terjadinya kecelakaan kerja pada Offshore Operation Facilities di PT. X. Hasil penelitian menunjukan terdapat 9 aktivitas dalam pekerjaan di Offshore CPP-Upper Compression Module dengan nilai RPN tertinggi pada aktivitas melakukan pengencangan mur dan baut dengan nilai 576 . Mitigasi dilakukan dengan memperbaiki sistem kerja dengan memperbaiki standar operasional prosedur khusus di area offshore facilities, menetapkan personel khusus untuk verifikasi seluruh dokumen kerja, melakukan sosialisasi kepada supervisor untuk peningkatan pengelolaan pekerjaan melalui perencanaan jadwal tenaga kerja yang dapat diverifikasi oleh sistem.
\end{abstract}

Kata kunci: FMEA; Mitigasi; Offshore; Risiko; RPN

\begin{abstract}
Industrialization in the oil and gas sector has a high risk of work accidents. The operations of oil and gas activities are divided into two, namely offshore and onshore. Offshore facilities are the exploration of natural gas owned by PT. $X$, which is located off the north coast of Java island with different forms of construction and very limited space for workers. Occupational safety and health factors are the main priority in carrying out activities carried out at the Offshore Facilities. The method of failure mode effect and analysis (FMEA) is a method implemented to identify the potential risks of work process failure by determining the impact and identifying actions to reduce work risks. The purpose of this study was to determine the factors that cause and mitigate risk by making recommendations for improvements to minimize the occurrence of work accidents at Offshore Operation Facilities at PT. $X$. The results showed that there were 9 activities in work at the Offshore CPP-Upper Compression Module with the highest RPN value in the activities of tightening nuts and bolts with a value of 576. Mitigation was done by improving the work system by improving the operational standard of special procedures in the offshore facilities area, establishing special personnel to verify all work documents, disseminating information to supervisors to improve work management through workforce planning that can be verified by the system.
\end{abstract}

Keywords: FMEA; Mitigation; Offshore; Risk; RPN 


\section{PENDAHULUAN}

Berdirinya industrialisasi di Indonesia semakin cepat dengan menawarkan tempat kerja yang beraneka ragam. Keberhasilan dalam melakukan aktivitasnya merupakan tujuan setiap perusahaan diantaranya berupa hasil produksi serta layanan (Siregar, Wahyuni, \& Nasution, 2019). Semakin pesat perkembangan industri maka semakin tinggi pula risiko bahaya kerja yang dihadapi dan berbagai macam alih teknologi dengan tingkat kompleksitas penggunaan mesin, peralatan kerja dalam siklus produksi.

Risiko didefinisikan sebagai peluang atau kemungkinan untuk kejadian atau kegagalan yang dapat menyebabkan konsekuensi (negatif) dalam bentuk kehilangan, kerusakan, cedera dan bahkan kematian bagi personel, fasilitas, dan lingkungan (Rosyid \& Jamil, 2017). Faktor kegagalan dalam proses kegiatan kerja dapat menimbulkan risiko kerja (Novianto, 2010). Potensi bahaya atau yang disebut hazard terdapat hampir di seluruh tempat kerja (Adiguna, Juniani, \& Nugroho, 2017). Risiko kerja dapat timbul akibat adanya kegiatan industri dalam proses produksi yang mengakibatkan terjadinya kecelakaan kerja. Kecelakaan kerja merupakan kondisi yang tidak dapat diduga dan diluar kontrol yang mengganggu proses suatu aktivitas. Risiko dapat diminimalisir dengan menyusun kebijakan keselamatan dan kesehatan kerja (Rusba et al., 2019). Identifikasi risiko dapat dilakukan melalui upaya pencegahan kecelakaan kerja (Ihsan, Edwin, \& Octavianus Irawan, 2017).

Proyek minyak dan gas selain butuh investasi modal besar juga mempunyai potensi risiko tinggi, keterlibatan banyak pihak, kompleksnya teknologi yang digunakan, serta dampak lingkungan bahkan sosial yang tinggi (Van Thuyet, Ogunlana, \& Dey, 2007). Operasi migas biasanya dibagi menjadi dua kegiatan utama, yaitu offshore dan onshore. Biasanya, operasi yang paling kritis dan operasi yang sangat berisiko biasanya berpusat di kegiatan offshore (Suda, Rani, Rahman, \& Chen, 2015). Secara umum, faktor risiko dan bahaya dapat diinduksi di sektor minyak dan gas dengan parameter yang terkandung dalam sistem industri (Bolado-Lavin et al., 2012). Berbagai macam standarisasi peraturan diterbitkan untuk mencegah terjadinya kecelakaan dalam kegiatan operasi hulu migas.

Berdasarkan surat edaran Direktur Teknik Pertambangan Migas selaku Kepala Inspeksi Tambang Migas tanggal 25 Oktober 1996, terdapat empat klasifikasi kecelakaan tambang yaitu ringan, sedang, berat, dan fatal. Angka ke- celakaan operasi kegiatan usaha hulu migas pada tahun 2014 sampai dengan 2018.

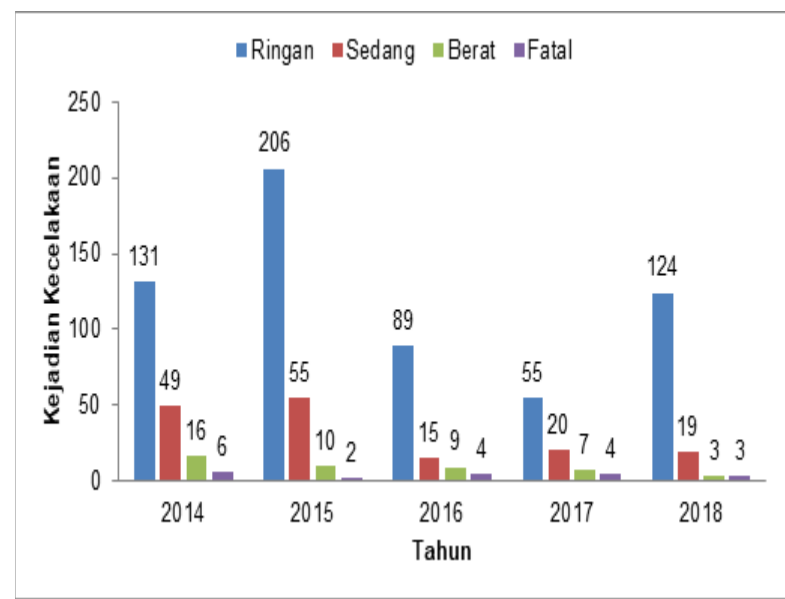

Gambar 1. Kecelakaan operasi kegiatan usaha hulu minyak dan gas bumi $2014-2018$

Sebagai perusahaan yang bergerak di bidang Migas, PT. X selalu dihadapkan pada risiko bahaya yang sangat tinggi. Risiko-risiko bahaya tersebut jika tidak dikelola dengan baik maka akan menimbulkan suatu kerugian baik terhadap manusia, bahan, peralatan maupun lingkungan. Berbagai macam hazard dapat timbul akibat adanya kegiatan operasi perusahaan sektor migas (Dwi Septalita, 2018). Offshore facilities merupakan area dari eksplorasi Gas Bumi yang dimiliki oleh PT. X yang berada dilepas pantai utara pulau jawa. Dari letak geografis Offshore Facilities berada di lepas pantai dan jauh dari daratan dengan bentuk konstruksi yang berbeda serta ruang gerak bagi pekerja yang sangat terbatas, sehingga faktor keselamatan dan kesehatan kerja merupakan prioritas utama dalam melaksanakan kegiatan yang dilakukan di Offshore Facilities.

Upaya untuk mengurangi dan menanggulangi risiko yang terjadi pada offshore facilities maka perlu diketahui risiko mana yang lebih dominan sebagai sumber penyebab terjadi risiko. Salah satu metode yang digunakan untuk mengidentifikasi terjadinya risiko akibat potensial kegagalan dalam aktivitas kerja adalah metode FMEA yang dapat mengukur tingkat risiko yang terjadi dengan tiga estimasi pengukuran yaitu severity, occurrence dan detection. Untuk mencegah terjadinya moda kegagalan dengan menggunakan skala prioritas melalui prosedur terstruktur dalam mengidentifikasi adalah metode FMEA (Irawan, Santoso, \& Mustaniroh, 2017).

Metode failure mode effect and analysis (FMEA) merupakan metode yang diimplementasikan untuk mengidentifikasi potensi risiko kegagalan proses pekerjaan dengan 
menentukan dampak dan mengidentifikasi tindakan untuk mengurangi risiko kerja (Ririh, Sundari, \& Wulandari, 2018) melalui analisis risiko sirkulatif (Gaspersz, 2002). Identifikasi kegagalan dilakukan menentukan tingkat potensial kejadian (Occurrence), tingkat keparahan (severity), dan tingkat deteksi (Detection) (Stamatis, 2003). Tujuan penelitian ini adalah mengetahui faktor yang menjadi penyebab dan tingkat risiko serta mitigasi terjadinya kecelakaan kerja dengan menyusun rekomendasi perbaikan yang tepat untuk meminimalisir terjadinya kecelakaan kerja pada Offshore Operation Facilities.

\section{METODE PENELITIAN}

Tahapan penelitian dibagi menjadi 2 bagian, pertama melakukan pengumpulan data informasi melalui brainstorming terhadap operator di offshore facilities untuk menetapkan kegiatan yang akan diidentifikasi dengan menyusun urutan pekerjaan serta bahaya masing-masing aktivitas untuk mengetahui faktor - faktor penyebab terjadinya kecelakaan kerja. Tahap kedua yaitu melakukan analisis terhadap bahaya yang ada dengan menggunakan failure mode effect and analysis (FMEA). Adapun tahapan dalam proses FMEA yaitu (1) meninjau proses kegiatan, (2) melakukan brainstorming untuk mengetahui potensi terjadinya kecelakaan kerja dari moda kegagalan potensial, (3) merangkum potensi bahaya yang ditimbulkan untuk setiap kecelakaan kerja, (4) memberikan peringkat severity untuk setiap potensi bahaya kecelakaan kerja (besarnya efek potensial) (Tabel 1), (5) menetapkan peringkat Occurrence (probabilitas kegagalan akan terjadi) (Tabel 2), (6) menetapkan peringkat Detection (probabilitas masalah terdeteksi sebelum kemunculannya) (Tabel 3), (7) menghitung Risk Priority Number (RPN) untuk setiap aktivitas kegiatan, (8) memprioritaskan aktivitas kegiatan pekerjaan yang mempunyai nilai RPN tertinggi untuk ditindak lanjuti, dan (9) memprioritaskan aktivitas kegiatan pekerjaan yang mempunyai nilai RPN tertinggi untuk ditindak lanjuti. Nilai RPN juga sebagai dasar penentuan keputusan dalam penentuan tingkat strategi perbaikan.

$\mathrm{RPN}=\mathrm{S} \times \mathrm{O} \times \mathrm{D}$
Tabel 1. Peringkat Severity

\begin{tabular}{|c|c|c|}
\hline Tkt & Dampak & Akibat Luka \\
\hline 10 & Kehilangan & $\begin{array}{ll}\text { Kematian } & \text { beberapa } \\
\text { individu (masal) }\end{array}$ \\
\hline 9 & $\begin{array}{l}\text { nyawa atau } \\
\text { merubah }\end{array}$ & $\begin{array}{l}\text { Kematian individu } \\
\text { (seseorang) }\end{array}$ \\
\hline 8 & $\begin{array}{l}\text { kehidupan } \\
\text { individu }\end{array}$ & $\begin{array}{l}\text { Perlu perawatan serius } \\
\text { dan menimbulkan cacat } \\
\text { permanen }\end{array}$ \\
\hline 7 & $\begin{array}{l}\text { Berdampak } \\
\text { besar pada }\end{array}$ & $\begin{array}{l}\text { Dirawat lebih dari } 12 \text { jam, } \\
\text { dengan luka pecah } \\
\text { pembuluh darah, hilang } \\
\text { ingatan hebat, kerugian } \\
\text { besar. }\end{array}$ \\
\hline 6 & $\begin{array}{l}\text { Individu } \\
\text { sehingga tidak } \\
\text { ikut lagi dalam } \\
\text { aktivitas }\end{array}$ & $\begin{array}{l}\text { Dirawat lebih dari } 12 \text { jam, } \\
\text { patah tulang, tulang } \\
\text { bergeser, radang dingin, } \\
\text { luka bakar, susah } \\
\text { bernafas dan lupa ingatan } \\
\text { sementara,jatuh/terpeleset }\end{array}$ \\
\hline 5 & $\begin{array}{l}\text { Dampak yang } \\
\text { diterima sedang }\end{array}$ & $\begin{array}{l}\text { Keseleo/terkilir, } \\
\text { retak/patah ringan, kram } \\
\text { atau kejang }\end{array}$ \\
\hline 4 & $\begin{array}{l}\text { beraktivitas } 1 \\
\text { sampai } 2 \text { hari) }\end{array}$ & $\begin{array}{l}\text { Luka bakar ringan, luka } \\
\text { gores/tersayat, frosnip } \\
\text { (radang dingin/panas) }\end{array}$ \\
\hline 3 & $\begin{array}{l}\text { Dampak } \\
\text { diterima kecil } \\
\text { (individu masih }\end{array}$ & $\begin{array}{l}\text { Melepuh, tersengat panas, } \\
\text { keseleo ringan, tergelincir } \\
\text { atau terpeleset ringan }\end{array}$ \\
\hline 2 & $\begin{array}{l}\text { dapat ikut dalam } \\
\text { aktivitas) }\end{array}$ & $\begin{array}{l}\text { Tersengat matahari, } \\
\text { memar, teriris ringan, } \\
\text { tergores }\end{array}$ \\
\hline 1 & $\begin{array}{l}\text { Tidak } \\
\text { berdampak }\end{array}$ & $\begin{array}{l}\text { Terkena } \\
\text { tersengat } \\
\text { serangga. }\end{array}$ \\
\hline
\end{tabular}

Sumber : (Wang, Chin, Poon, \& Yang, 2009)

Tabel 2. Peringkat Occurrence

\begin{tabular}{|c|c|c|}
\hline Probabilitas Kejadian & $\begin{array}{l}\text { Tingkat } \\
\text { kejadian }\end{array}$ & Nilai \\
\hline \multirow{2}{*}{$\begin{array}{l}\text { Sangat tinggi dan tidak } \\
\text { bisa dihindari }\end{array}$} & $>1$ in 2 & 10 \\
\hline & 1 in 3 & 9 \\
\hline \multirow{2}{*}{$\begin{array}{lll}\text { Tinggi dan } & \text { sering } \\
\text { terjadi }\end{array}$} & 1 in 8 & 8 \\
\hline & 1 in 20 & 7 \\
\hline \multirow{2}{*}{$\begin{array}{l}\text { Sedang dan kadang } \\
\text { terjadi }\end{array}$} & 1 in 80 & 6 \\
\hline & 1 in 400 & 5 \\
\hline \multirow{2}{*}{$\begin{array}{l}\text { Rendah dan relatif } \\
\text { jarang terjadi }\end{array}$} & 1 in 2.000 & 4 \\
\hline & 1 in 15.000 & 3 \\
\hline \multirow{2}{*}{$\begin{array}{l}\text { Sangat rendah dan } \\
\text { hampir tidak pernah } \\
\text { terjadi }\end{array}$} & $\begin{array}{l}1 \\
150.000\end{array}$ & 2 \\
\hline & $\begin{array}{l}1 \text { in } \\
1.500 .000\end{array}$ & 1 \\
\hline
\end{tabular}

Sumber : (Wang et al., 2009) 
Tabel 3. Peringkat Detection

\begin{tabular}{|c|c|c|}
\hline Deteksi & $\begin{array}{l}\text { Kemungkinan } \\
\text { Terdeteksi }\end{array}$ & Rangking \\
\hline $\begin{array}{l}\text { Hampir } \\
\text { tidak } \\
\text { mungkin }\end{array}$ & $\begin{array}{l}\text { Tidak ada alat } \\
\text { pengontrol yang } \\
\text { mampu mendeteksi }\end{array}$ & 10 \\
\hline $\begin{array}{l}\text { Sangat } \\
\text { jarang }\end{array}$ & $\begin{array}{lr}\text { Alat pengontrol saat } \\
\text { ini sangat } & \text { sulit } \\
\text { mendeteksi } & \text { bentuk } \\
\text { dan } & \text { penyebab } \\
\text { kegagalan } & \end{array}$ & 9 \\
\hline Jarang & $\begin{array}{lr}\text { Alat pengontrol saat } \\
\text { ini sangat } & \text { sulit } \\
\text { mendeteksi } & \text { bentuk } \\
\text { dan } & \text { penyebab } \\
\text { kegagalan } & \end{array}$ & 8 \\
\hline $\begin{array}{l}\text { Sangat } \\
\text { Rendah }\end{array}$ & $\begin{array}{lr}\text { Kemampuan } & \text { alat } \\
\text { kontrol } & \text { untuk } \\
\text { mendeteksi } & \text { bentuk } \\
\text { dan penyebab } & \text { sangat } \\
\text { rendah } & \end{array}$ & 7 \\
\hline Rendah & $\begin{array}{l}\text { Kemampuan alat } \\
\text { kontrol untuk } \\
\text { mendeteksi bentuk } \\
\text { dan penyebab rendah }\end{array}$ & 6 \\
\hline Sedang & $\begin{array}{lr}\text { Kemampuan } & \text { alat } \\
\text { kontrol } & \text { untuk } \\
\text { mendeteksi } & \text { bentuk } \\
\text { dan penyebab sedang }\end{array}$ & 5 \\
\hline $\begin{array}{l}\text { Agak } \\
\text { Tinggi }\end{array}$ & $\begin{array}{l}\text { Kemampuan alat } \\
\text { kontrol } \\
\text { mendeteksi bentuk } \\
\text { dan penyebab sedang } \\
\text { sampai } \\
\text { tinggi }\end{array}$ & 4 \\
\hline Tinggi & $\begin{array}{l}\text { Kemampuan alat } \\
\text { kontrol untuk } \\
\text { mendeteksi bentuk } \\
\text { dan penyebab tinggi }\end{array}$ & 3 \\
\hline $\begin{array}{l}\text { Sangat } \\
\text { Tinggi }\end{array}$ & $\begin{array}{lr}\text { Kemampuan } & \text { alat } \\
\text { kontrol } & \text { untuk } \\
\text { mendeteksi } & \text { bentuk } \\
\text { dan penyebab sangat } \\
\text { tinggi }\end{array}$ & 2 \\
\hline $\begin{array}{l}\text { Hampir } \\
\text { Pasti }\end{array}$ & $\begin{array}{lr}\text { Kemampuan } & \text { alat } \\
\text { kontrol } & \text { untuk } \\
\text { mendeteksi } & \text { bentuk } \\
\text { dan penyebab hampir } & \\
\text { pasti } & \end{array}$ & 1 \\
\hline
\end{tabular}

Sumber : (Wang et al., 2009)

\section{HASIL DAN PEMBAHASAN}

Berdasarkan hasil identifikasi terhadap aktivitas pekerjaan dapat diperoleh maka ditetapkan aktivitas yang akan diidentifikasi adalah kegiatan Offshore CPP - Upper Compression Module (tabel 4).
Tabel 4. Kegiatan Offshore CPP-Upper Compression Module

\begin{tabular}{|c|c|c|}
\hline No. & Aktivitas & Bahaya \\
\hline 1 & $\begin{array}{l}\text { Bongkar 18" Spool } \\
\text { Line }\end{array}$ & $\begin{array}{ll}\text { Jari } & \text { tangan } \\
\text { terjepit } & \text { Torque } \\
\text { Wrench } & \end{array}$ \\
\hline 2 & $\begin{array}{l}\text { Mobilize 18" Spool } \\
\text { dari CPP ke Welding } \\
\text { Shop di AUP }\end{array}$ & $\begin{array}{l}\text { Kaki kejatuhan } \\
18 \text { " spool line }\end{array}$ \\
\hline 3 & $\begin{array}{l}\text { Instal Weldolet } \\
\text { Injection Quill }\end{array}$ & $\begin{array}{l}\text { Terkena percikan } \\
\text { api saat proses } \\
\text { welding }\end{array}$ \\
\hline 4 & $\begin{array}{l}\text { Uji NDT dan } \\
\text { Hidrostatik }\end{array}$ & $\begin{array}{l}\text { Terkena bocoran } \\
\text { material }\end{array}$ \\
\hline 5 & $\begin{array}{l}\text { Mobilize } 18 \text { "Spool } \\
\text { dari Welding Shop di } \\
\text { AUP ke } \\
\text { CPP }\end{array}$ & $\begin{array}{l}\text { Kaki kejatuhan } \\
18 \text { " spool line }\end{array}$ \\
\hline 6 & $\begin{array}{l}\text { Instal Ulang Spool } 18 \\
\text { " }\end{array}$ & $\begin{array}{l}\text { Tangan tergores } \\
\text { dan kaki terjepit }\end{array}$ \\
\hline 7 & $\begin{array}{l}\text { Mengencangkan Nuts } \\
18 \text { " Menggunakan } \\
\text { Alat Pneumatik }\end{array}$ & $\begin{array}{l}\text { Tangan terjepit } \\
\text { alat pneumatik }\end{array}$ \\
\hline 8 & $\begin{array}{l}\text { Pasang injeksi Quill } 2 \\
\text { "\& Heading IP ke } \\
\text { Welding Shop untuk } \\
\text { Memotong Baut }\end{array}$ & $\begin{array}{l}\text { Terkena percikan } \\
\text { api dan terjepit } \\
\text { alat enerpac }\end{array}$ \\
\hline 9 & $\begin{array}{l}\text { Melakukan } \\
\text { pengencangan } \\
\text { dan baut }\end{array}$ & $\begin{array}{l}\text { Jari telunjuk kiri } \\
\text { terjepit di antara } \\
\text { Kunci Pas } \\
\text { Enerpac dan mur }\end{array}$ \\
\hline
\end{tabular}

Kegiatan pekerjaan Offshore CPP - Upper Compression Module. t ke dalam 9 aktivitas kerja.. Selanjutnya menentukan nilai Severity, Occurance dan Detection digunakan data hasil kuesioner, maka diperoleh nilai S,O,D dan RPN (Tabel 5). Berdasarkan hasil pengolahan data menggunakan data FMEA maka diperoleh nilai RPN tertinggi yaitu pada aktivitas melakukan pengencangan mur dan baut dengan nilai 576 yang artinya mempunyai risiko tinggi terhadap potensial terjadinya kecelakaan kerja dan efek yang ditimbulkan. Untuk itu aktivitas ini mempunyai risiko kecelakaan kerja tertinggi pada pekerjaan yang dilakukan di Offshore Facilities. Tahap selanjutnya yaitu melakukan mitigasi risiko terhadap aktivitas yang mempunyai nilai RPN tertinggi, hasil mitigasi risiko untuk mengurangi terjadinya risiko (Tabel 6) dengan temuan utama operator tidak pernah menangani pekerjaan semacam ini sebelumnya, tidak ada verifikasi paket kerja, tidak ada metode pernyataan dan / atau tidak ada prosedur kerja dalam paket kerja, pemanfaatan kunci torsi enerpac tidak disebutkan dalam izin kerja (PTW) dan penilaian risiko tugas (TRA) dan juga dalam daftar peralatan 
tidak cukup istirahat $(+/-3$ jam $)$

Tabel 5. Nilai $S O D$ dan RPN

\begin{tabular}{|c|c|c|c|c|c|c|}
\hline No. & Aktivitas & $\mathrm{S}$ & $\mathrm{O}$ & $\mathrm{D}$ & RPN & Rating \\
\hline 1 & $\begin{array}{l}\text { Bongkar 18" } \\
\text { Spool Line }\end{array}$ & 6 & 5 & 7 & 210 & 4 \\
\hline 2 & $\begin{array}{lr}\text { Mobilize } & 18 " \\
\text { Spool } & \text { dari } \\
\text { CPP } & \text { ke } \\
\text { Welding } & \text { Shop } \\
\text { di AUP } & \end{array}$ & 7 & 4 & 5 & 140 & 7 \\
\hline 3 & $\begin{array}{l}\text { Instal } \\
\text { Weldolet } \\
\text { Injection Quill }\end{array}$ & 4 & 7 & 6 & 168 & 6 \\
\hline 4 & $\begin{array}{l}\text { Uji NDT dan } \\
\text { Hidrostatik }\end{array}$ & 6 & 5 & 6 & 180 & 5 \\
\hline 5 & $\begin{array}{lr}\text { Mobilize } & 18 \\
\text { "Spool dari } \\
\text { Welding Shop } \\
\text { di AUP ke } \\
\text { CPP }\end{array}$ & 7 & 4 & 4 & 112 & 8 \\
\hline 6 & $\begin{array}{l}\text { Instal Ulang } \\
\text { Spool 18" }\end{array}$ & 4 & 6 & 3 & 72 & 9 \\
\hline 7 & $\begin{array}{l}\text { Mengencangk } \\
\text { an Nuts 18" } \\
\text { Menggunakan } \\
\text { Alat } \\
\text { Pneumatik }\end{array}$ & 6 & 7 & 7 & 294 & 3 \\
\hline 8 & $\begin{array}{l}\text { Pasang } \\
\text { injeksi Quill } 2 \\
\text { "\& Heading IP } \\
\text { ke Welding } \\
\text { Shop untuk } \\
\text { Memotong } \\
\text { Baut }\end{array}$ & 7 & 6 & 8 & 336 & 2 \\
\hline 9 & $\begin{array}{l}\text { Melakukan } \\
\text { pengencanga } \\
\mathrm{n} \text { mur dan } \\
\text { baut }\end{array}$ & 8 & 8 & 9 & 576 & 1 \\
\hline
\end{tabular}

Berdasarkan hasil mitigasi yang dilakukan maka dapat diketahui bahwa kegiatan di offshore facilities harus dilakukan dengan mengutamakan standart operasional prosedur yang telah ditetapkan perusahaan, hal ini dikarenakan offshore facilities merupakan area eksplorasi yang dibangun dengan konstruksi khusus dengan bentuk dan luas yang terbatas serta lokasi yang jauh dari daratan, sehingga dibutuhkan keahlian khusus dalam melakukan pekerjaan. faktor risiko proyek di industri migas benar-benar kompleks sehingga analisis risiko harus dilakukan untuk mengatasi berbagai aspek proyek, lingkungan, serta kejadian bencana serta diintegrasikan dengan aspek pembangunan berkelanjutan (Rodhi, Anwar, \& Wiguna, 2017)
Tabel 6. Mitigasi Risiko

\begin{tabular}{|c|c|c|}
\hline No. & Temuan & Mitigasi \\
\hline 1 & $\begin{array}{l}\text { Operator tidak } \\
\text { pernah } \\
\text { menangani } \\
\text { pekerjaan } \\
\text { semacam ini } \\
\text { sebelumnya }\end{array}$ & $\begin{array}{lr}\text { Mengembangkan } & \text { sistem } \\
\text { (misal Instruksi Kerja, } & \text { Kar } \\
\text { Daftar Periksa) Untuk } & \text { atau } \\
\text { menilai } & \text { menugaskan personel } \\
\text { sebelum melaksanakan } & \\
\text { pekerjaan }\end{array}$ \\
\hline 2 & $\begin{array}{l}\text { Tidak } \\
\text { verifikasi } \\
\text { Kerja }\end{array}$ & $\begin{array}{l}\text { Tetapkan personel } \\
\text { khusus (mis. Coordinator } \\
\text { Workpack) untuk mem- } \\
\text { verifikasi semua } \\
\text { dokumen pendukung } \\
\text { yang tercantum dalam } \\
\text { daftar Workpack telah } \\
\text { selesai. }\end{array}$ \\
\hline 3 & $\begin{array}{lr}\text { Tidak } & \text { Ada } \\
\text { Metode } & \\
\text { Pernyataan dan / } \\
\text { atau Tidak Ada } \\
\text { Prosedur } & \text { Kerja } \\
\text { dalam } & \text { Paket } \\
\text { Kerja } & \end{array}$ & $\begin{array}{l}\text { Tetapkan personel } \\
\text { khusus (mis. Coordinator } \\
\text { Workpack) untuk me- } \\
\text { mastikan Prosedur Kerja } \\
\text { tersedia dalam Paket } \\
\text { Kerja. }\end{array}$ \\
\hline 4 & \begin{tabular}{lr}
\multicolumn{3}{l}{ Pemanfaatan } \\
Kunci & Torsi \\
Enerpac & tidak \\
disebutkan dalam \\
lzin Kerja & (PTW) \\
dan & Penilaian \\
Risiko & Tugas \\
(TRA) dan juga \\
dalam \\
peralatan
\end{tabular} & 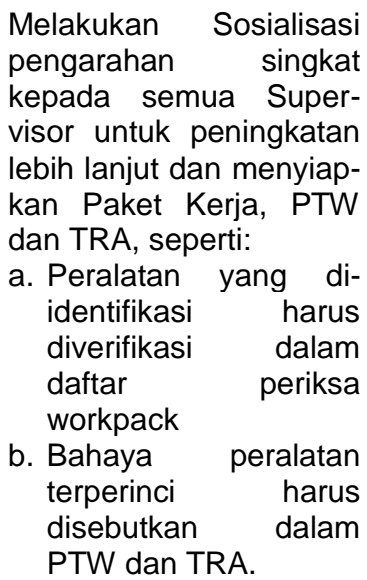 \\
\hline 5 & 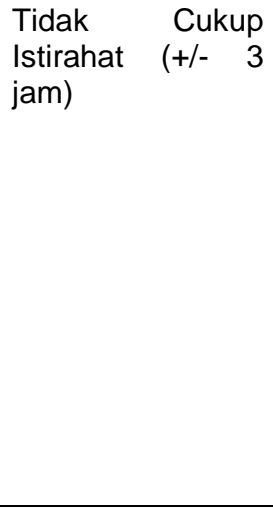 & $\begin{array}{l}\text { Melakukan Sosialisasi } \\
\text { untuk memberi pe- } \\
\text { ngarahan singkat kepada } \\
\text { semua Supervisor untuk } \\
\text { peningkatan lebih lanjut } \\
\text { dalam mengelola } \\
\text { pekerjaan, seperti: } \\
\text { a. Perencanaan dan } \\
\text { penjadwalan tenaga } \\
\text { kerja } \\
\text { b. Pengaturan kerja } \\
\text { harus didentifikasi, } \\
\text { diverifikasi, dan di- } \\
\text { kelola dengan baik. }\end{array}$ \\
\hline
\end{tabular}

\section{KESIMPULAN}

Berdasarkan hasil analisis yang telah dilakukan, maka dapat disimpulkan bahwa terdapat 9 aktivitas dalam pekerjaan di Offshore CPP-Upper Compression Module yang mempunyai potensial risiko yang dapat terjadi disebabkan oleh kurangnya keterampilan yang 
dimiliki oleh pekerja yang tidak mempunyai sertifikasi keahlian. Sedangkan hasil perhitungan terhadap nilai Risk Priority Number (RPN) tertinggi yaitu pada aktivitas melakukan pengencangan mur dan baut dengan nilai RPN sebesar 576. Mitigasi yang dilakukan untuk mengurangi terjadinya risiko adalah memperbaiki sistem kerja dengan memperbaiki standar operasional prosedur khusus di area offshore facilities, menetapkan personel khusus untuk verifikasi seluruh dokumen kerja, melakukan sosialisasi kepada supervisor untuk peningkatan pengelolaan pekerjaan melalui perencanaan jadwal tenaga kerja yang dapat diverifikasi oleh sistem. Setelah dilakukan perbaikan melalui pengukuran risiko, maka penelitian selanjutnya dapat dilakukan assessment terhadap tingkat kompetensi yang dimiliki oleh pekerja dan peralatan yang digunakan harus dilakukan pengecekan dan kalibrasi alat lebih lanjut.

\section{DAFTAR PUSTAKA}

Adiguna, P., Juniani, A. I., \& Nugroho, A. (2017). Teknik Identifikasi Bahaya Dan Pengendalian Resiko Pada Panggung Gas Osigen PT Aneka Gas Industri V. Seminar K3, 1(1), 77-81.

Bolado-Lavin, R., Gracceva, F., Zeniewski, P., Zastera, P., Vanhoorn, E., \& Menqulini, A. (2012). Best practices and methodological guidelines for conducting gas risk assessments. Luxembourg.

Dwi Septalita, E. (2018). Kecelakaan Kerja Di Area Pengeboran Minyak Dan Gas Tahun 2012 - 2016. The Indonesian Journal of Occupational Safety and Health, 7(1), 52.

Gaspersz, V. (2002). Pedoman implementasi program six sigma terintegrasi dengan ISO 9001: 2000, MBNQA, dan HACCP. Jakarta: PT. Gramedia Pustaka Utama.

Ihsan, T., Edwin, T., \& Octavianus Irawan, R. (2017). Analisis Risiko K3 Dengan Metode Hirarc Pada Area Produksi Pt Cahaya Murni Andalas Permai. Jurnal Kesehatan Masyarakat Andalas, 10(2), 179-185. https://doi.org/10.24893/jkma.v10i2.204

Irawan, J. P., Santoso, I., \& Mustaniroh, S. A. (2017). Model Analisis dan Strategi Mitigasi Risiko Produksi Keripik Tempe Model Analysis and Mitigation Strategy of Risk in Tempe Chips Production. Industria: Jurnal Teknologi Dan Manajemen Agroindustri, 6(2), 88-96.

Novianto, F. (2010). Analisis Kecelakaan dan Kesehatan Kerja dan Upaya Pencegahannya di Bagian Flooring dengan Pendekatan Risk Assesment PT. Dharma Satya Nusantara Surabaya. Skripsi.
Surabaya: Fakultas Teknologi Industri. Universitas Pembangunan Nasional "Veteran":

Ririh, K. R., Sundari, A. S., \& Wulandari, P. (2018). Analisis Risiko Pada Area Finishing Menggunakan Metode Failure Mode Effect And Analysis (FMEA) Di PT. Indokarlo Perkasa. SEMRESTEK 2018 Proceedings, 1(1), 631-640.

Rodhi, N. N., Anwar, N., \& Wiguna, I. P. A. (2017). A Review on Risk Factors in the Project of Oil and Gas Industry. IPTEK The Journal for Technology and Science, 28(3), 63-67.

Rosyid, D. M., \& Jamil, M. Y. (2017). Risk Assessment of Onshore Pipeline in Area Gresik. International Journal of Offshore and Coastal Engineeing, 1(1), 29-34.

Rusba, K., Hardiyono, H., AL, J. E., Siboro, I., Pongky, P., \& Tobarasi, I. (2019). Implementasi Keselamatan Kerja Pada Pembuatan Area Drilling Rig Dengan Pendekatan Task Risk Assesment (Studi Kasus: Pada XYZ Indonesia Di Kalimantan Timur). Jurnal Public Policy, 5(2), 123-133.

Siregar, K. N., Wahyuni, W., \& Nasution, R. M. (2019). Penetapan Kebijakan K3 serta Perencanaan K3 Dan Implikasinya terhadap Kejadian Kecelakaan Kerja di PKS Kebun Rambutan PTPN-III Tebing Tinggi. Jurnal Kesehatan Global, 2(1), 1-7.

Stamatis, D. H. (2003). Failure mode and effect analysis: FMEA from theory to execution. ASQ Quality press.

Suda, K. A., Rani, N. S. A., Rahman, H. A., \& Chen, W. (2015). A Review on Risks and Project Risks Management: Oil and Gas Industry. International Journal of Scientific Engineering, 6(8), 938-943.

Van Thuyet, N., Ogunlana, S. O., \& Dey, P. K. (2007). Risk management in oil and gas construction projects in Vietnam. International Journal of Energy Sector Management, 1(2), 175-194.

Wang, Y.-M., Chin, K.-S., Poon, G. K. K., \& Yang, J.-B. (2009). Risk evaluation in failure mode and effects analysis using fuzzy weighted geometric mean. Expert Systems with Applications, 36(2), 1195-1207. 